\title{
The Action Difference of Lasiodiplodia theobromae on Infecting and Dyeing Poplar Wood in Spatial Growth
}

\author{
Yuansong Liu, Yunxiao Gao, Zhiming Yu* and Yang Zhang
}

check for updates

Citation: Liu, Y.; Gao, Y.; Yu, Z.; Zhang, Y. The Action Difference of Lasiodiplodia theobromae on Infecting and Dyeing Poplar Wood in Spatial Growth. Coatings 2021, 11, 985. https://doi.org/10.3390/ coatings 11080985

Academic Editor: Marko Petric

Received: 21 July 2021

Accepted: 16 August 2021

Published: 19 August 2021

Publisher's Note: MDPI stays neutral with regard to jurisdictional claims in published maps and institutional affiliations.

Copyright: (c) 2021 by the authors. Licensee MDPI, Basel, Switzerland. This article is an open access article distributed under the terms and conditions of the Creative Commons Attribution (CC BY) license (https:/ / creativecommons.org/licenses/by/ $4.0 /)$.
College of Materials Science and Technology, Beijing Forestry University, Beijing 100083, China; liuyuansong2018@bjfu.edu.cn (Y.L.); CLgyx01@bjfu.edu.cn (Y.G.); bjfuzhangyang@bjfu.edu.cn (Y.Z.)

* Correspondence: yuzhiming@bjfu.edu.cn

\begin{abstract}
Many factors affect the driving force of fungal growth and secretion. To compare the differences of Lasiodiplodia theobromae infected poplar wood, the changes of physical and chemical properties of vertically and horizontally infected poplar wood before and after dyeing were analyzed, and the infection characteristics were studied in this paper. The horizontal infection was more effective than the vertical infection in terms of infection depth, color depth, and microscopic hyphal invasion. The mycelium first intruded into the earlywood tissue and began to secrete a large amount of pigment after twenty days. The crystallinity of mycelium decreased slightly, and the difference in weight loss rate was negligible. The initial contact angle of the dyed specimen on the horizontal infection increased drastically in distilled water, but there was almost no difference between varnish and natural coating. The horizontal infection was more efficient than the vertical infection and had a higher color depth and a better induction effect, which is crucial in future microbial dyeing.
\end{abstract}

Keywords: Lasiodiplodia theobromae; poplar; dyeing; infecting

\section{Introduction}

The development of synthetic pigments started with the industrial revolution in Europe, and then began to develop rapidly and continuously [1]. Compared with natural pigments, synthetic pigments have a series of advantages, such as low price, bright color, and a high degree of industrialization [2-4]. In the last hundred years following the industrial revolution in Europe, people have successfully produced millions of compounds with assorted colors. Among them, tens of thousands of pigments have been industrialized, but environmental pollution and harm to the human body caused by synthetic dyes have attracted increasing attention, resulting in limited application [5-8].

In recent years, with the gradual improvement of environmental protection and safety awareness, natural pigments are relatively safe, environmentally compatible, and biodegradable. Some natural dyes have medicinal value, such as antibacterial [9] and antitumor [10], thus they can also be widely used in medical and health care [11]. In addition, the natural dye's safety and environmental-friendly processes allow them to be used in the manufacturing of cosmetics, such as for lipstick color enhancers, and for skin and hair dyeing $[12,13]$. Natural dyes are currently used in many fields, such as food and beverage, industrial plastics, paper making, handicraft, daily chemical products, and the pharmaceutical industry [14-16]. As a result, natural pigments have been revalued and have broad development prospects.

Natural dyes refer to dyes obtained directly from nature without chemical processing $[17,18]$. Depending on the source, they can be classified into plant, animal, or mineral dyes. The most widely used plant natural dyes are mainly extracted from plant roots, stems, and leaves [19,20]. Animal dyes are mainly shellac and cochineal [21,22]. Mineral dyes are colored, inorganic metal salts and metal oxides; mainly brown-red and light green metal substances $[23,24]$. However, mineral dyes are no longer used because of safety and environmental protection problems. According to application classification, 
natural dyes are divided into direct application and mordant dyeing types. The direct natural dyes have good water solubility and can be adsorbed directly on the fiber $[25,26]$. However, most natural dyes are not currently used due to the disadvantages of color uptake, light resistance, acid and alkali resistance, and colorfastness, which can be realized by employing mordant dyeing. Colorfastness once became a major and challenging issue in the utilization of natural pigments $[27,28]$. Although the research on natural dyes has a long history, there are still many problems with natural dyes research. For example, plant dye extraction, which is the most widely studied, has the disadvantages of being high-cost and a complex process. For wood material with low value and requiring dye decoration, natural dyes are an economical and environmentally friendly material to apply in wood dyeing; the source of dye content cannot meet the growing demand which limits the pace of industrial development of natural dyes. Microbial pigment is a new source of pigment. This new dyeing technology mainly cultures the microorganisms that secrete pigment, which are inoculated onto materials, or the pigment is extracted to be used as a dye [29-31]. Microorganisms used in the production of pigments have the advantages of low cost, fast-growth speed, are not affected by the origin and climate conditions, and have gradually attracted the attention of researchers and enterprises. Therefore, microbial pigments have increasingly become the focus of scientific research [32,33].

In the field of microbiological staining, Robinson's research team has done many research works. Two strains of Scytalidium cuboideum capable of producing red stain in culture were inoculated onto sugar maple (Acer saccharum Marsh), incubated for 6-14 weeks, and evaluated for their ability to produce a high-saturation penetrating stain [34]. In addition, sugar maple, Norway maple, and aspen logs were incubated in a temperature and humidity-controlled chamber for 12 weeks to show laboratory level spalting and had achievable and highly predictable results [35]. Beech and sugar maple blocks placed within a modified decay jar system to promote fungal pigments production were incubated for 10 weeks [36]. Blue-stained lodgepole pine was used for spalting treatment with Scytalidium species incubation for 12 weeks and showed the pink or yellow color on the wood [37]. Vega Gutierrez [38] tried to use fungal pigments in bamboo, natural spalting for 4-16 weeks, and the direct application of extracted fungal pigments of Scytalidium cuboideum, Scytalidium ganodermophthorum, and Chlorociboria aeruginosa were compared. The results showed that the pigment extracted from the fungi could be used for surface treatment of bamboo, while the inner coloring was only achieved by direct inoculation of S. cuboideum. These studies on microbial dyeing have opened up a new research idea of microbial pigment in wood and bamboo. However, these inoculations need an extended test period and much time to complete the inoculation and staining.

The better dyeing effect can be observed from the cross-sectional infection of fungi due to the longitudinal infection channels $[34,39]$. In this study, the methods of cross-sectional infection in a vertical and horizontal direction were used to achieve microbial staining. First, the fungi was isolated from Lasiodiplodia theobromae, then a blue-stained piece of wood was used as the staining fungus, potato dextrose agar medium was used as the basic culture medium, and tyrosinase and tricyclazole were used as inducers. The fungi were inoculated in a fast-growing poplar (Populus euramevicana, I-107) for 10, 20, 30 and 40 days. The experiment compared and analyzed the infection characteristics of the two dyeing methods and resulting wood properties, hoping to shorten the dyeing cycle time and provide some reference for the wood microbial dyeing research.

\section{Materials and Methods}

\subsection{Materials and Chemical Agents}

Lasiodiplodia theobromae (Pat.) (CFCC 84471) purchased from the China Forestry Culture Collection Center was used in this study (isolated from blue stained poplar). The size of poplar wood specimens was processed to $50 \times 50 \times 20 \mathrm{~mm}^{3}$ (Huaqing Wood Industry Co., Ltd. Heze, China) with $0.55 \mathrm{~g} / \mathrm{cm}^{3}$ average density and $6.5 \%$ moisture content. 
The specimen was taken from the sapwood of the same batch of poplar, each group had 6 duplicate test pieces.

PDA (Potato Dextrose Agar) medium was a solid medium composed of $200 \mathrm{~g}$ of potato, $20 \mathrm{~g}$ of glucose, and 15-20 g of agar with a natural $\mathrm{pH}$ (Beijing AoBoXing Bio-Tech co., Ltd., Beijing, China); Tyrosinase (Shanghai Yuanye Biotechnology Co., Ltd., Shanghai, China), CAS: 9002-10-2; Tricyclazole (Shanghai new platinum Chemical Technology Co., Ltd., Shanghai, China), CAS: 41814-78-2, analytical purity standard.

\subsection{Biological Dyeing Process}

To test the difference of infection effect of Lasiodiplodia theobromae in vertical and horizontal directions of poplar cross-section, the direction of wood specimen was set in a cross-section upward (Vertical infection, L) and a cross-section towards the sides (Horizontal infection, W), without edge sealing treatment. However, half of the thickness of the horizontally infected wood specimen was below the nutrient substrate level to verify that fungi would not grow from the bottom of the specimen. The inoculation position of the vertical infection was on the cross-section surface, while the horizontal infection position was on the culture medium to ensure vertical and horizontal infection effectiveness. As shown in the infection diagram in Figure 1, the basic culture medium was PDA, and either a tyrosinase or a tricyclazole inducer was added to make induction medium ((1) control, (2) tyrosinase, and (3) tricyclazole). The specimens were cultured in a humidity box with a constant temperature of $28^{\circ} \mathrm{C}$ and relative air humidity of $85 \%$ for 10 (A), 20 (B), 30 (C), and 40 (D) days. After dyeing, the dyed wood was sterilized by a pressure steam sterilizer (pressure $0.111 \mathrm{MPa}$, temperature $121^{\circ} \mathrm{C}$ ). After sterilization, the mycelium on the surface of the wood was removed and dried in a constant temperature drying oven at $40{ }^{\circ} \mathrm{C}$ to a moisture content of $8 \%-12 \%$.

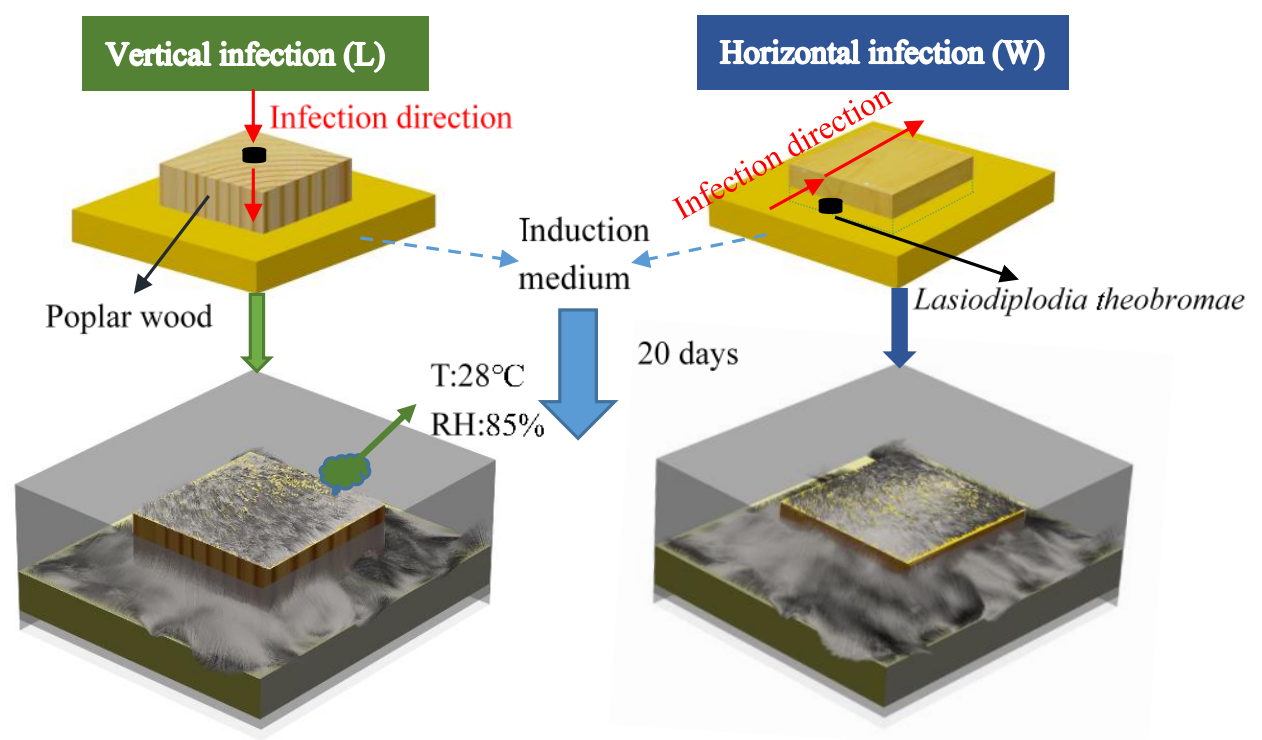

Figure 1. Biological dyeing process of vertical and horizontal infection of poplar wood by Lasiodiplodia theobromae.

\subsection{Instruments and Equipment}

Constant Temperature and Humidity Box (\#HWS-80B, Beijing Huasheng Scientific Instrument Laboratory Equipment Co., Ltd., Beijing, China); Pressure steam sterilizer (\#YX-280, Hefei Huatai Medical Equipment Co., Ltd., Hefei, China); Super Clean Workbench (\#SW-CJ-1D, Beijing Huasheng Scientific Instrument Laboratory Equipment Co., Ltd., Beijing, China); Fourier transform infrared spectroscope (FTIR, \#Nicolet iS5, 400$4000 \mathrm{~cm}^{-1}$ of the detection wavelength, Thermo Fisher Scientific, Waltham, MA, USA); Optical Contact Angle Meter (\#Dataphysics-OCA, Stuttgart, Germany); Scanning elec- 
tron microscope (\#GeminiSEM 300, Oberkochen, Germany); Colorimeter (\#Dataflash 110, Shanghai Dingzheng Instrument Equipment Co., Ltd., Shanghai, China); Electric drying oven (\#DHG-9075a, Beijing Huianming Technology Development Co., Ltd., Beijing, China); pH meter (\#PB-10, Sartorius Group, Göttingen, Germany); Rotatory viscometer (\#NDJ-1, Shanghai Yoke Instrument Co., Ltd., Shanghai, China). Thermo Gravimetry- Differential Thermal Analysis (TG-DSC, \#NETZSCH STA 449F3); X-ray diffractometer (XRD, \#Ultima IV, Rigaku Corporation, Tokyo, Japan).

\subsection{Measurements}

\subsubsection{Chromaticity Value Test}

The chromaticity value and chromatic aberration comparison in the dyeing test is a common and significant test. In this experiment, the chromaticity value of the cross-section of Lasiodiplodia theobromae infected poplar wood was measured, and the chromatic aberration in different dyeing times was compared. Specific test methods refer to Liu [40,41].

\subsubsection{Microsection Analysis}

To analyze fungi entering into the wood and dyeing in different directions, the microscopic observation of the dyed wood was carried out, and the difference of growth and secretion characteristics of fungi in the wood between the two infection methods was compared. The specimen was taken from the center of the dyed wood, and the radial section or tangential section of dyeing wood was selected for observation.

\subsubsection{Chemical Composition Analysis}

Although the two infection ways have the same infection channel, the infection degree of wood needs to be detected and identified due to the difference in hyphae entering into the wood and the direction of contact with the wood. Therefore, FTIR (the test wavelength was $525-4000 \mathrm{~cm}^{-1}$ and scanned 32 times), XRD (the scanning angle was 5-90', and the scanning speed was $5^{\circ} / \mathrm{min}$ ), and TG-DSC (under nitrogen protection, heat the sample from room temperature to $40{ }^{\circ} \mathrm{C}$, keep the sample at $40{ }^{\circ} \mathrm{C}$ for $1 \mathrm{~min}$ to ensure uniform temperature distribution, and then heat it to $1000^{\circ} \mathrm{C}$ at the heating rate of $20^{\circ} \mathrm{C} / \mathrm{min}$ ) were used to test the infected wood.

\subsubsection{Surface Characteristics}

Distilled water (viscosity: $0.9 \mathrm{mPa} \cdot \mathrm{s}, \mathrm{pH}$ : 6.8) and two commonly used wood surface treatment solvents were used to test the contact angle of dyed wood, and the other two solvents were varnish (viscosity: $90 \mathrm{mPa} \cdot \mathrm{s}, \mathrm{pH}$ : 7.8, solid content: $26.05 \%$ ) and natural coating (viscosity: $3575 \mathrm{mPa} \cdot \mathrm{s}, \mathrm{pH}$ : 7.4 , solid content: $29.74 \%$ ), respectively, to test the difference of contact angle of the wood surface before and after dyeing (Test conditions: $30 \mathrm{~s}$ of test time, $2 \mu \mathrm{L}$ of droplet size, room temperature environment).

\section{Results and Discussion}

\subsection{Visual Staining Phenomenon}

Figure 2a shows the difference between vertical and horizontal infection of poplar wood after 20 and 40 days of induced dyeing. After twenty days post-vertical infection, the fungal dyeing of the tyrosinase induction group had penetrated $20 \mathrm{~mm}$ wood specimen. Compared with the other two groups of infected poplar wood, the tyrosinase induction group has better infection uniformity, while in horizontal infection, a significant difference can be observed in infected poplar wood regarding infection depth and color between 20 and 40 days after dyeing. After 40 days of dyeing, the woodblock with a width of $50 \mathrm{~mm}$ had been thoroughly infected, and the horizontal infection was much better than the vertical infection in tricyclazole induction. Due to the effect of nutrient solution absorption and inducer, the horizontal infection was stronger than that of vertical infection, which ensured the continuity and effectiveness of induction. In addition, the poplar's internal dyed parts were analyzed and tested by a colorimeter to understand the internal dyeing 
situation of the wood. The chromatic aberration before and after dyeing was tested by a colorimeter (Figure $2 b$ ), and the color simulation was carried out according to the collected colorimetric values (Figure 3). The color difference between the two infection methods was not obvious in 20 days, but the horizontal infection was significantly greater than the vertical infection after 40 days.
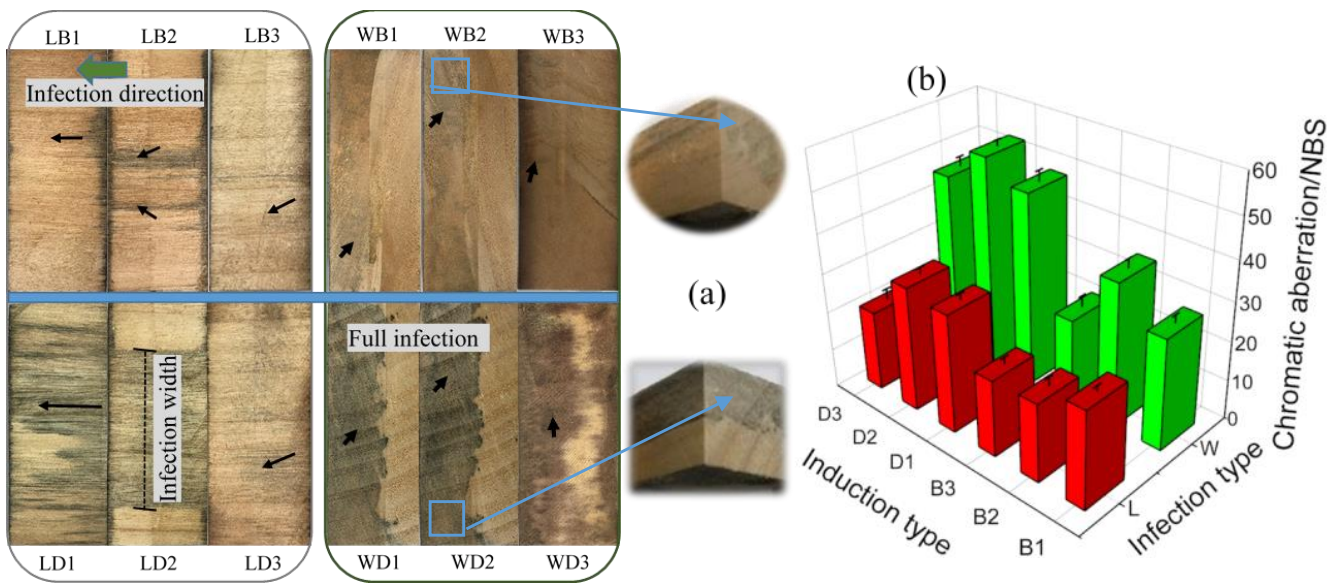

Figure 2. (a) Dyeing graph and (b) chromatic aberration of vertical and horizontal dyeing of poplar wood by Lasiodiplodia theobromae after 20 and 40 days. (LB1 stands for vertical infection-20 dayscontrol group).

LB
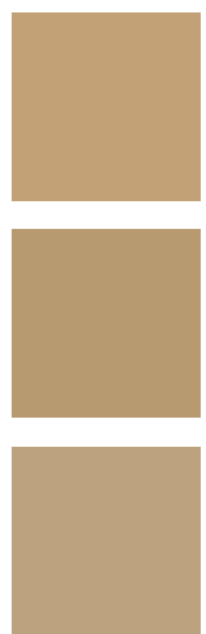

LD
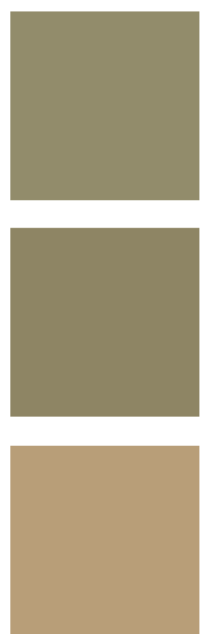

WB
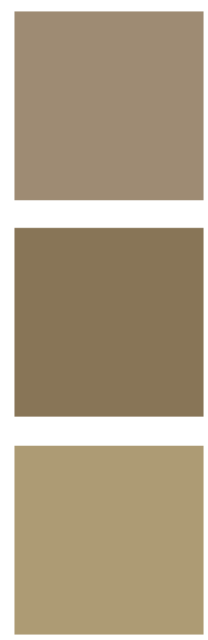

WD

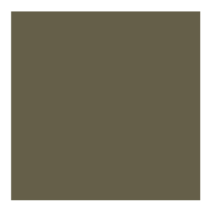

Control

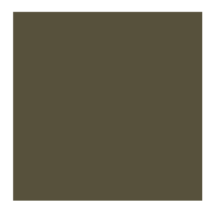

Ty

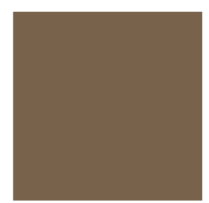

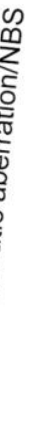




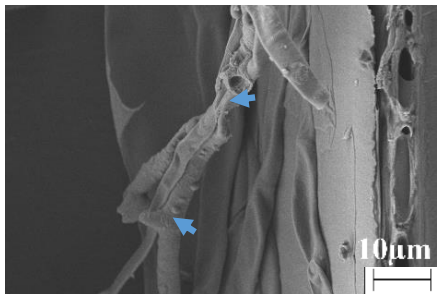

(a) LDI

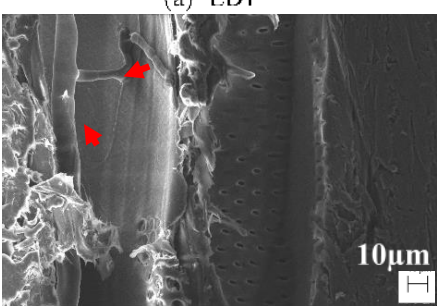

(d) WD1

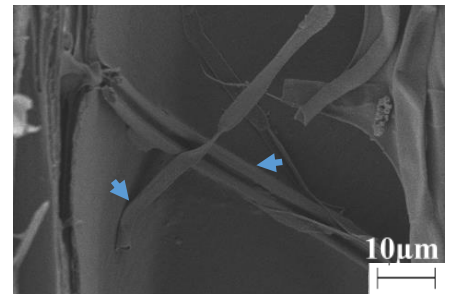

(b) LD2

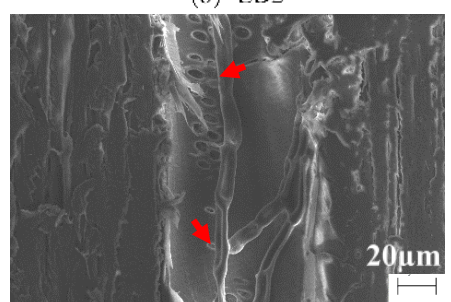

(e) WD2

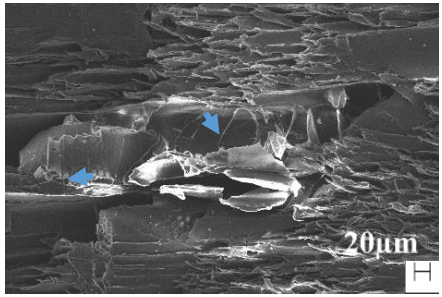

(c) LD3

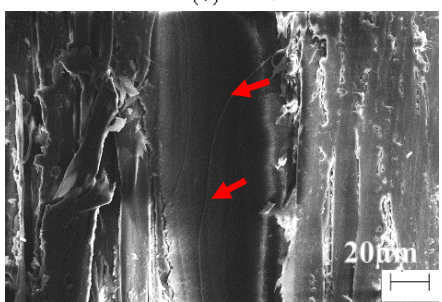

(f) WD3

Figure 4. Micromorphology of vertical $(\mathbf{a}-\mathbf{c})$ and horizontal dyeing $(\mathbf{d}-\mathbf{f})$ of poplar wood by Lasiodiplodia theobromae after 40 days. (The arrow indicates the position of mycelium).

\subsection{Infective Characters}

According to the apparent color changes and microscopic fungal infection of dyed wood, the essential difference between the two dyeing methods was the absorption of the nutrient solution by L. theobromae and the inducer effect, which showed the difference in the uniformity, speed, and color difference of dyeing. Figure 5 shows the schematic diagram of the two infection modes, the vertical infection hyphae first covered the surface of the wood with a layer of hyphae and began to infect the interior of the wood. During horizontal infection, the hyphae usually covered the surface of the wood first and then infected the interior of the wood through the vessels of cross-section according to the time of contacting the wood. The earlywood was the first tissue invaded by hyphae; the amount of pigment secretion was less in the early stage of invasion, and a large amount of pigment secretion began after 20 days, which was more effective than vertical infection.

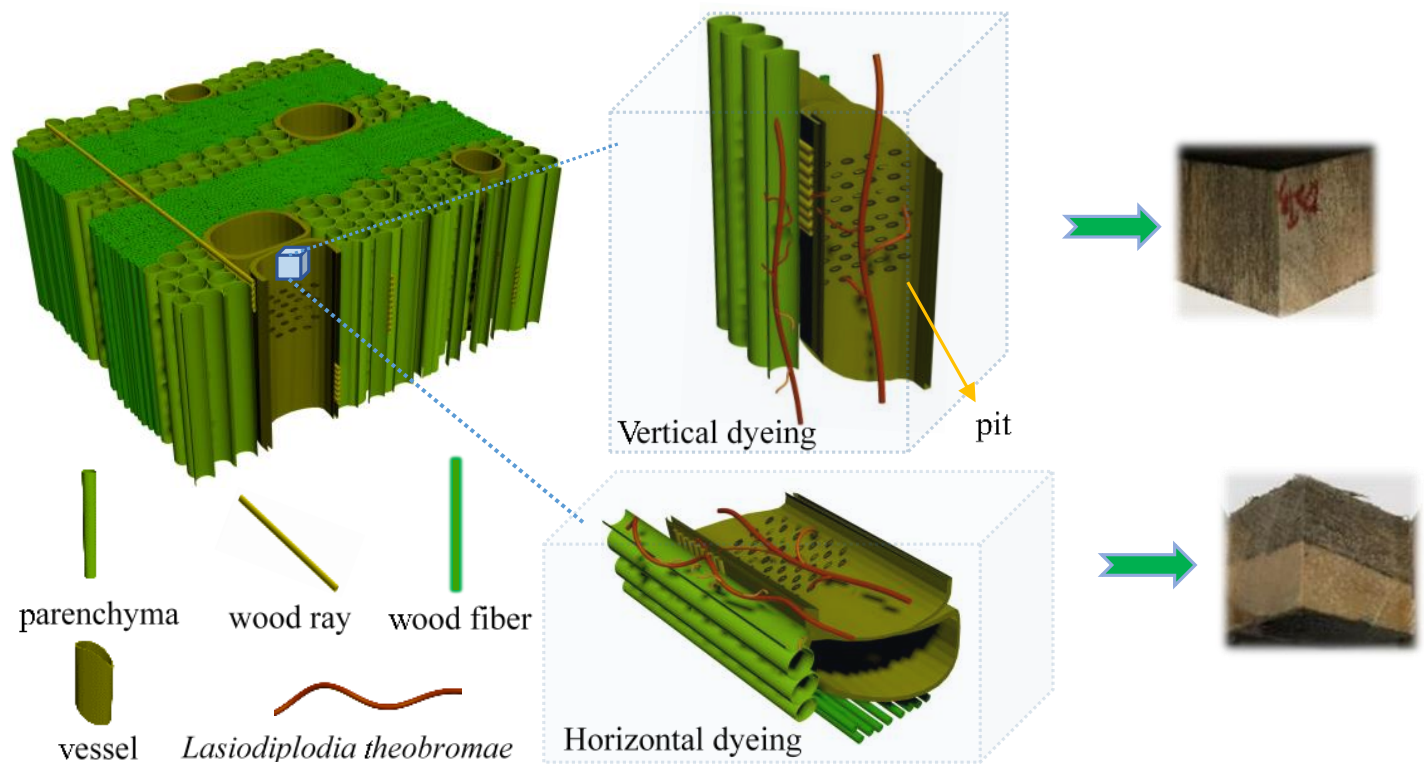

Figure 5. Infective characters of vertical and horizontal dyeing of poplar wood by Lasiodiplodia theobromae. 


\subsection{Chemical Composition}

The growth of hyphae is accompanied by the secretion of cell wall degrading enzymes, such as cellulase $\left(C_{x}\right)$, hemicellulase, and ligninase, which consume the cell wall components and destroy the wood structure. This experiment explored the changes in the composition and structure of dyed poplar wood and selected the horizontal infection method with a better infection effect to test the dyed poplar wood (Figure 6). The infrared spectrum showed that there are 2342 and $2360 \mathrm{~cm}^{-1}$ characteristic peaks in the dyed wood, which should be the main structural substance of the pigment secreted by fungi, and it was speculated that this substance was the stretching vibration of the $\mathrm{C}-\mathrm{C}$ triple bond [42]. In addition, there were characteristic peaks of $1029 \mathrm{~cm}^{-1}$ (aromatic $C-C$ structure or the stretching vibrations of $\mathrm{C}-\mathrm{O}-\mathrm{C}$ ) and $668 \mathrm{~cm}^{-1}$ in-plane $\mathrm{C}-\mathrm{H}$ bending deformation and out-of-plane $\mathrm{C}-\mathrm{H}$ deformation [43], and the intensity of these peaks increased. In general, the infrared analysis of chemical components of dyed wood did not show the characteristic peak which disappeared or weakened obviously, so it was speculated that it had little effect on the composition and structural strength of wood.

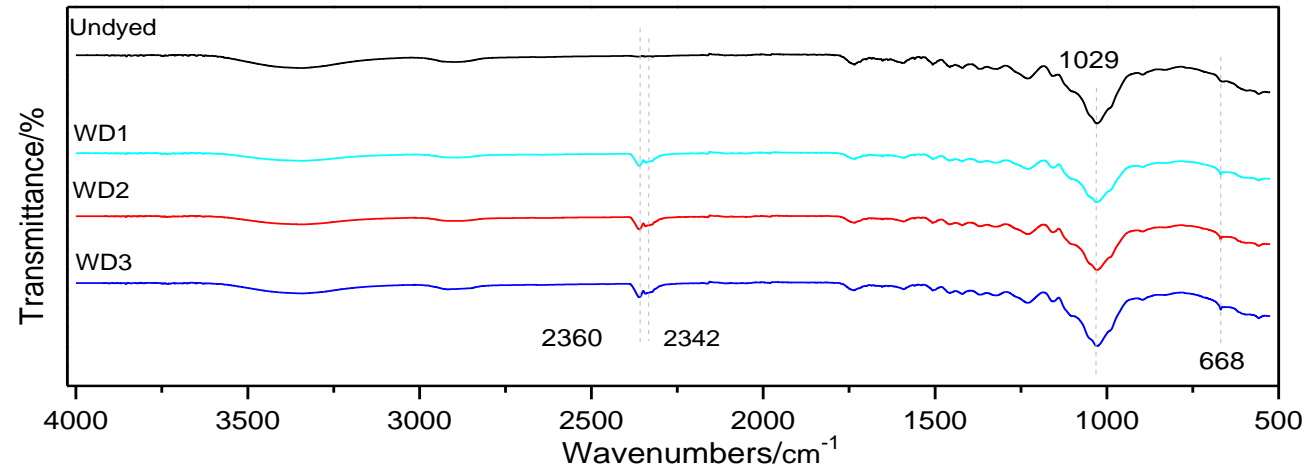

Figure 6. Changes of chemical components of poplar wood in vertical and horizontal dyeing by Lasiodiplodia theobromae after 40 days under different induction factors.

Calculation of crystallinity based on X-ray diffraction pattern [44] (Segal): X-ray crystallinity $(\mathrm{XC})=\left(\mathrm{I}_{002}-\mathrm{I}_{\mathrm{am}}\right) / \mathrm{I}_{002} \times 100 \%$, of which $\mathrm{I}_{002}$ is $002\left(22.0^{\circ}\right)$ of the diffraction intensity of the crystal plane, $\mathrm{I}_{\mathrm{am}}\left(18.0^{\circ}\right)$ is the diffraction intensity of the amorphous region. The crystallinity was $38.17 \%, 33.52 \%, 33.29 \%$, and $34.82 \%$, respectively, from the control group to the tricyclazole induced group (Undyed, WD1, WD2, WD3). The crystallinity of the infected wood was similar but slightly decreased (Figure 7), indicating that the growth and secretion of fungi in the wood had a certain effect on the cellulose crystallization area. TG test showed that the gap value of the weight loss rate of each group was $1.87 \%$, and the biggest weight loss rate was the untreated group (Figure 8a). DSC test showed that two exothermic peaks appeared at $300^{\circ} \mathrm{C}$ and $600{ }^{\circ} \mathrm{C}$ and had a slight difference in the endothermic peak area (Figure $8 \mathrm{~b}$ ). This should be due to the influence of pigment secreted by fungi or the individual differences.

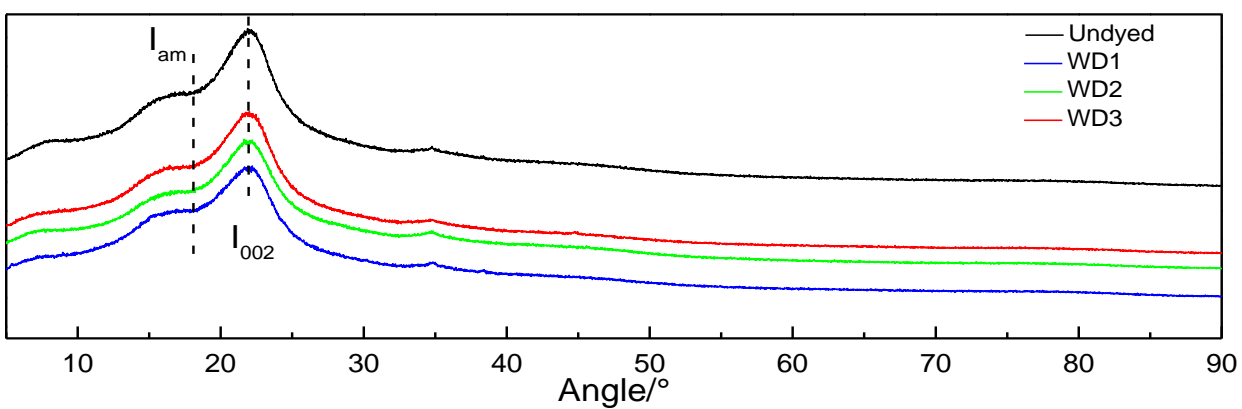

Figure 7. X-ray diffraction images of poplar wood infected for 40 days under different induction factors. 

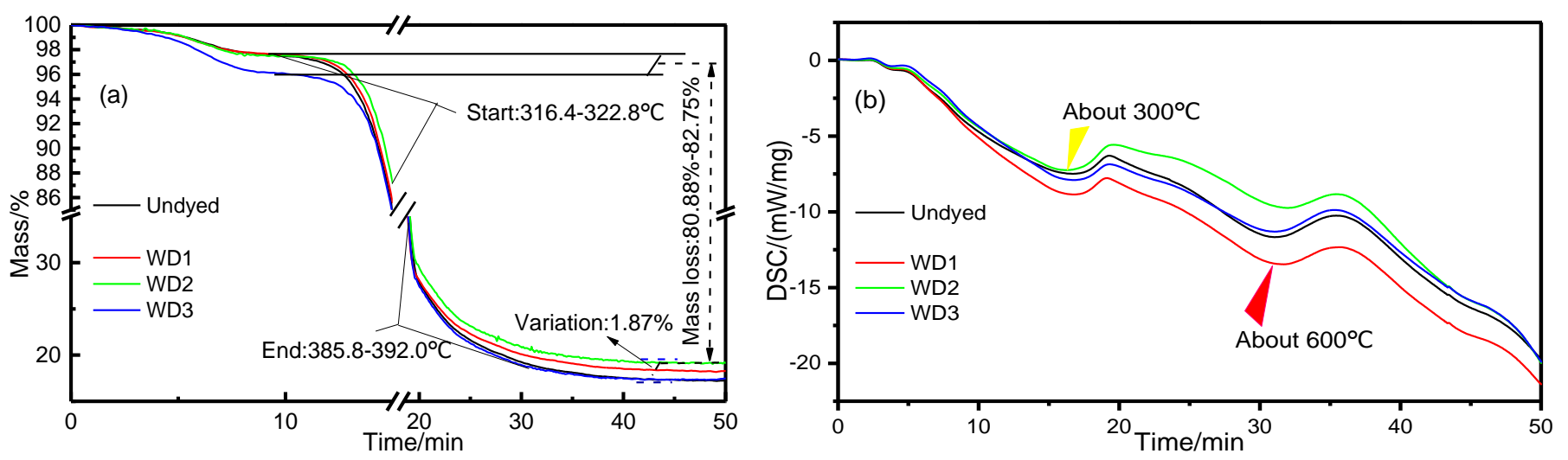

Figure 8. TG (a)-DSC (b) analysis of poplar wood infected for 40 days under different induction factors.

\subsection{Wettability}

The contact angle test was carried out by selecting the poplar wood with a better dyeing effect. As shown in Figure 9, the initial contact angle of horizontal dyed wood in distilled water increases obviously compared with other groups, but the initial contact angle of varnish and natural coating on dyed wood was almost the same as that of untreated wood. The reason was that varnish and natural coating both have a relatively high viscosity and molecular weight. The two liquids had a large wood contact angle in normal conditions, and the partial mycelium from dyed wood was filled with the channel for the solvent to pour into the interior. Therefore, the transmission channel of water molecules was narrowed compared with untreated wood, which was more obvious compared with other solvents. Figure $9 \mathrm{~b}$ shows the typical dynamic curves of three solvents in wood. The higher the molecular weight and viscosity, the smaller the change rate of the contact angle.
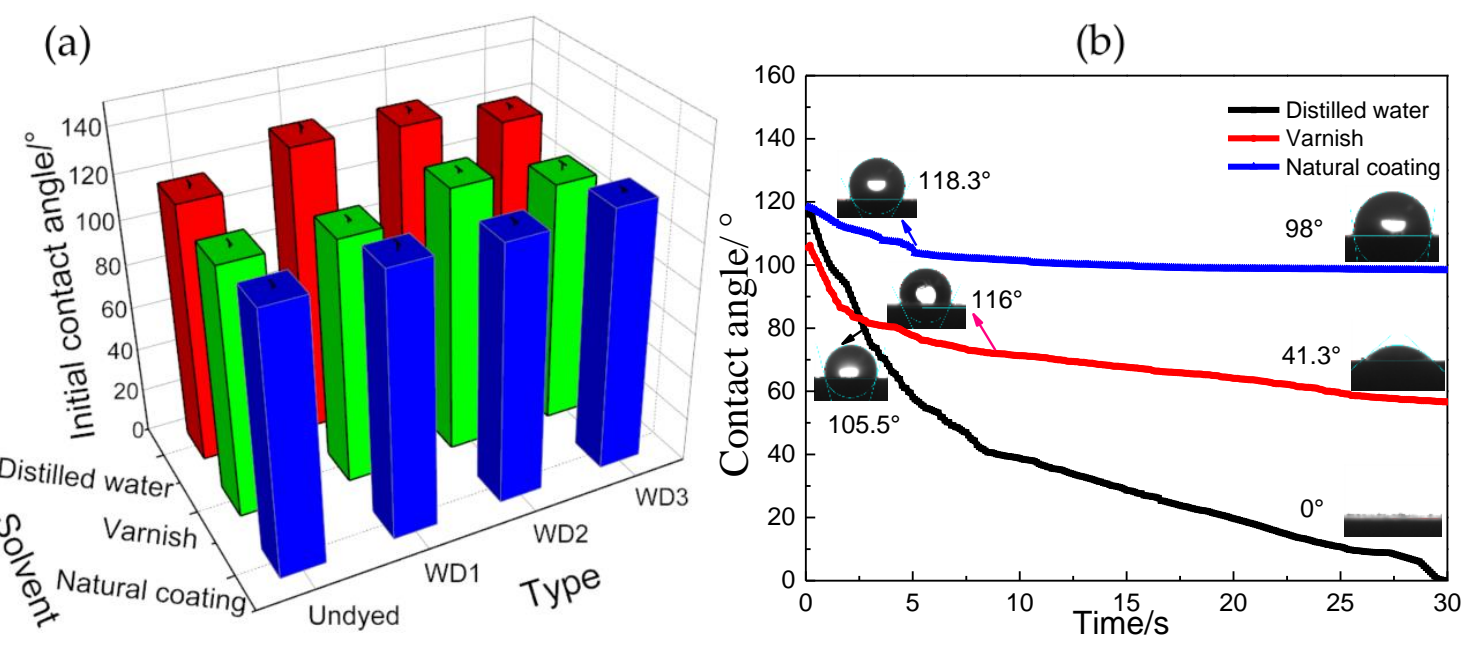

Figure 9. Initial contact angle (a) and typical dynamic contact angle curve (b) of poplar in different types and induction factors under the solvent of distilled water, varnish, and natural coating.

\section{Conclusions and Outlook}

In this experiment, the color difference of horizontal infected poplar wood was significantly greater than that of vertically infected poplar wood after 40 days of dyeing, with a larger infection depth and color depth, especially in the tricyclazole induced group. The number of hyphae was more abundant in the horizontal infection than in the vertical infection. The hyphae invaded the tissue of earlywood first and began to secrete much pigment after 20 days. There were prominent characteristic peaks of 2342 and $2360 \mathrm{~cm}^{-1}$ in the dyed poplar wood, accompanied by a slight decrease in crystallinity and a small 
difference in weight loss rate, which had a minor effect on the wood composition and structural strength on the whole. In addition, the initial contact angle of the samples dyed with distilled water increased obviously, but in varnish and natural coating, there was almost no difference with untreated wood.

Although the direct infection of microorganisms on wood can achieve a better dyeing effect, it is unrealistic to reach the level of industrialization in the long run, which needs large-scale industrial equipment, culture environment, and long dyeing cycle time. Therefore, it requires relatively superior technology to produce and extract pigment by microorganisms, such as fermentation culture. Fungal natural dyes can be produced in large quantities with a short culture period, low production cost, and no resource or environmental restrictions.

Author Contributions: Y.L.: Conceptualization, Methodology, Validation, Formal analysis, Investigation, Data curation, Writing-original draft, Writing-review \& editing, Visualization. Y.G.: Data curation, Validation. Z.Y.: Conceptualization, Methodology, Validation, Resources, Writing-review \& editing, Supervision, Project administration, Funding acquisition. Y.Z.: Methodology, Software. All authors have read and agreed to the published version of the manuscript.

Funding: This work was financially supported by the Beijing Excellent Talents Training Plan (No. 2017000020124G092).

Institutional Review Board Statement: Not applicable.

Informed Consent Statement: Not applicable.

Data Availability Statement: The data used to support the findings of this study are available from the corresponding author upon request.

Conflicts of Interest: We declare that we do not have any commercial or associative interest that represents a conflict of interest in connection with the work submitted.

\section{References}

1. Gao, H.G.; Gong, W.J.; Zhao, Y.G. Rapid method for quantification of seven synthetic pigments in colored Chinese steamed buns using UFLC-MS/MS without SPE. Anal. Sci. 2015, 31, 205-210. [CrossRef]

2. Lomax, S.Q. The application of X-ray powder diffraction for the analysis of synthetic organic pigments. Part 1: Dry pigments. J. Coat. Technol. Res. 2010, 7, 331-346. [CrossRef]

3. Zahroojian, N.; Moravej, H.; Shivazad, M. Comparison of marine algae (Spirulina platensis) and synthetic pigment in enhancing egg yolk colour of laying hens. Br. Poult. 2011, 52, 584-588. [CrossRef]

4. Ghelardi, E.; Degano, I.; Colombini, M.P.; Mazurek, J.; Schilling, M.; Khanjian, H.; Learner, T. A multi-analytical study on the photochemical degradation of synthetic organic pigments. Dyes Pigment. 2015, 123, 193-403. [CrossRef]

5. Ali, H. Biodegradation of synthetic dyes-A Review. Water Air Soil Pollut. 2010, 213, 251-273. [CrossRef]

6. Li, X.Q.; Zhang, Q.H.; Ma, K.; Li, H.M.; Guo, Z. Identification and determination of 34 water-soluble synthetic dyes in foodstuff by high performance liquid chromatography-diode array detection-ion trap time-of-flight tandem mass spectrometry. Food Chem. 2015, 182, 316-326. [CrossRef]

7. Chen, V.J.; Smith, G.D.; Holden, A.; Paydar, N.; Kiefer, K. Chemical analysis of dyes on an Uzbek ceremonial coat: Objective evidence for artifact dating and the chemistry of early synthetic dyes. Dyes Pigment. 2016, 131, 320-332. [CrossRef]

8. Atav, R.; Güneş, E.; Çifçi, D.İ.; Güneş, Y. Comparison of wool fabric dyeing with natural and synthetic dyes in view of ecology and treatability. AATCC J. Res. 2020, 7, 15-22. [CrossRef]

9. Deveoglu, O.; Muhammed, A.; Fouad, A.; Torgan, E.; Karaadag, R. Chromatographic analysis of natural pigments produced from Datisca cannabina L. and quercus infectoria Oliv. plants and their antimicrobial activity. J. Chem. Soc. Pak. 2012, 34, 890-895. Available online: https:/ /link.gale.com/apps/doc/A301252551/AONE (accessed on 17 August 2021).

10. Maoka, T.; Mochida, K.; Kozuka, M.; Ito, Y.; Fujiwara, Y.; Hashimoto, K.; Enjo, F.; Ogata, M.; Nobukuni, Y.; Tokuda, H.; et al. Cancer chemopreventive activity of carotenoids in the fruits of red paprika Capsicum annuum L. Cancer Lett. 2001, 172, 103-109. [CrossRef]

11. Hu, Y.L.; Luo, J.Y.; Hu, S.R.; Fu, H.; Yang, S.H.; Yang, M.H. Application of natural plant pigments in enlarged health industry. China J. Chin. Mater. Med. 2017, 42, 2433-2438. [CrossRef]

12. Castaneda, M.P.; Hirschler, E.M.; Sams, A.R. Skin pigmentation evaluation in broilers fed natural and synthetic pigments. Poult. Sci. 2005, 84, 143. [CrossRef]

13. Hu, Y.L.; Luo, J.Y.; Zhao, H.Z.; Zhang, S.S.; Yang, S.H.; Yang, M.H. Application of natural plant pigment in hair dyes. China J. Chin. Mater. Med. 2016, 41, 3226-3231. [CrossRef] 
14. Cortez, R.; Luna-Vital, D.A.; Margulis, D.; Gonzalez de Mejia, E. Natural pigments: Stabilization methods of anthocyanins for food applications. Compr. Rev. Food Sci. Food Saf. 2017, 16, 180-198. [CrossRef]

15. Myungsun, Y. Study on the development of plastic color using natural pigments-Focusing on Charcoal, lacquer, loess. J. Digit. Des. 2012, 12, 309-318. [CrossRef]

16. Rimkiene, S.; Ragazinskiene, O.; Savickiene, N. The cumulation of wild pansy (Viola tricolor L.) accessions: The possibility of species preservation and usage in medicine. Medicina 2003, 39, 411-416. [PubMed]

17. Fernández-López, J.A.; Fernández-Lledó, V.; Angosto, J.M. New insights into red plant pigments: More than just natural colorants. RSC Adv. 2020, 10, 24669-24682. [CrossRef]

18. Leong, H.Y.; Show, P.L.; Lim, M.H.; Ooi, C.W.; Ling, T.C. Natural red pigments from plants and their health benefits: A review. Food Rev. Int. 2018, 34, 463-482. [CrossRef]

19. Scott-Moncrieff, R. Natural anthocyanin pigments: The magenta flower pigment of Primula polyanthus. Biochem. J. 1930, 24, 767-778. [CrossRef]

20. Boo, H.O.; Hwang, S.J.; Bae, C.S.; Park, S.H.; Heo, B.G.; Gorinstein, S. Extraction and characterization of some natural plant pigments. Ind. Crops Prod. 2012, 40, 129-135. [CrossRef]

21. Baird, P.; Dan, R.; Hink, S.A. A remote marking device and newly developed permanent dyes for Wildlife research. Wildl. Soc. Bull. 2017, 41, 785-795. [CrossRef]

22. Hober, R.; Moore, E. Studies concerning the nature of the secretory activity of the isolated ringer-perfused frog liver. J. Gen. Physiol. 1939, 23, 191-202. [CrossRef]

23. Yang, X.; Wan, X. Analysis of the spectral reflectance and color of mineral pigments affected by their particle size. Color Res. Appl. 2020, 45, 246-261. [CrossRef]

24. Siddall, R. Mineral pigments in archaeology: Their analysis and the range of available materials. Minerals 2018, 8, 201. [CrossRef]

25. Dehnavi, E.; Shams-Nateri, A.; Khalili, H. Wool dyeing with binary mixture of natural dyes. Pigment. Resin Technol. 2016, 45, 52-61. [CrossRef]

26. Ding, Y.; Freeman, H.S. Mordant dye application on cotton: Optimisation and combination with natural dyes. Color. Technol. 2017, 133, 369-375. [CrossRef]

27. Sheikh, J.; Jagtap, P.S.; Teli, M.D. Ultrasound assisted extraction of natural dyes and natural mordants vis a vis dyeing. Fibers Polym. 2016, 17, 738-742. [CrossRef]

28. Sanli, H.S.; Kayabasi, N.; Lmez, F.N. Dyeing techniques and mordanting methods applied in natural dyeing of wool in Turkey. Asian J. Chem. 2011, 23, 3313-3316.

29. Robinson, S.C.; Tudor, D.; Cooper, P.A. Wood preference of spalting fungi in urban hardwood species. Int. Biodeterior. Biodegrad. 2011, 65, 1145-1149. [CrossRef]

30. Robinson, S.C.; Gutierrez, S.M.V.; Garcia, R.A.C.; Iroume, N.; Vorland, N.R.; McClelland, A.; Huber, M.; Stanton, S. Potential for carrying dyes derived from spalting fungi in natural oils. J. Coat. Technol. Res. 2017, 14, 1107-1113. [CrossRef]

31. Liu, Y.S.; Yu, Z.M.; Zhang, Y.; Wang, H.W. Microbial dyeing for inoculation and pigment used in wood processing: Opportunities and challenges. Dyes Pigment. 2021, 186, 109021. [CrossRef]

32. Ramesh, C.; Vinithkumar, N.V.; Kirubagaran, R.; Venil, C.K.; Dufossé, L. Multifaceted applications of microbial pigments: current knowledge, challenges and future directions for public health implications. Microorganisms 2019, 7, 186. [CrossRef] [PubMed]

33. Sen, T.; Barrow, C.J.; Deshmukh, S.K. Microbial pigments in the food industry—challenges and the way forward. Front. Nutr. 2019, 6, 7. [CrossRef] [PubMed]

34. Robinson, S.C.; Tudor, D.; Cooper, P.A. Feasibility of using red pigment producing fungi to stain wood for decorative applications. Can. J. For. Res. 2011, 41, 1722-1728. [CrossRef]

35. Robinson, S.C.; Tudor, D.; Hipson, S.; Snider, H.; Ng, S.; Korshikov, E.; Cooper, P.A. Methods of inoculating Acer spp. Populus tremuloides, and Fagus grandifolia logs for commercial spalting applications. J. Wood Sci. 2013, 59, 351-357. [CrossRef]

36. Robinson, S.C.; Tudor, D.; Cooper, P.A. Promoting fungal pigment formation in wood by utilizing a modified decay jar method. Wood Sci. Technol. 2012, 46, 841-849. [CrossRef]

37. Robinson, S.C.; Tudor, D.; MacDonald, G.; Mansourian, Y.; Cooper, P.A. Repurposing mountain pine beetle blue wood for art through additional fungal colonization. Int. Biodeterior. Biodegrad. 2013, 85, 372-374. [CrossRef]

38. Vega Gutierrez, S.M.; Vega Gutierrez, P.T.; Godinez, A.; Pittis, L.; Huber, M.; Stanton, S.; Robinson, S.C. Feasibility of coloring bamboo with the application of natural and extracted fungal pigments. Coatings 2016, 6, 37. [CrossRef]

39. Kamperidou, V. The biological durability of thermally-and chemically-modified black pine and poplar wood against basidiomycetes and mold action. Forests 2019, 10, 1111. [CrossRef]

40. Liu, Y.S.; Zhang, Y.; Yu, Z.M.; Qi, C.S.; Tang, R.L.; Zhao, B.S.; Wang, H.W.; Han, Y.Y. Microbial dyes: Dyeing of poplar veneer with melanin secreted by Lasiodiplodia theobromae isolated from wood. Appl. Microbiol. Biotechnol. 2020, 104, 3367-3377. [CrossRef]

41. Liu, Y.S.; Yu, Z.M.; Zhang, Y.; Qi, C.S.; Tang, R.L.; Zhao, B.S.; Wang, H.W.; Han, Y.Y. Microbial dyeing-infection behavior and influence of Lasiodiplodia theobromae in poplar veneer. Dyes Pigment. 2019, 173, 107988. [CrossRef]

42. Rassabina, A.E.; Gurjanov, O.P.; Beckett, R.P.; Minibayeva, F.V. Melanin from the lichens Cetraria islandica and Pseudevernia furfuracea: Structural features and physicochemical properties. Biochemistry 2020, 85, 623-628. [CrossRef] 
43. Girdthep, S.; Sirirak, J.; Daranarong, D.; Daengngern, R.; Chayabutra, S. Physico-chemical characterization of natural lake pigments obtained from Caesalpinia Sappan Linn. and their composite films for poly (lactic acid)-based packaging materials. Dyes Pigment. 2018, 157, 27-39. [CrossRef]

44. Segal, L.G.J.M.A.; Creely, J.J.; Martin, A.E., Jr.; Conrad, C.M. An empirical method for estimating the degree of crystallinity of native cellulose using the X-ray diffractometer. Text. Res. J. 1959, 29, 786-794. [CrossRef] 